\title{
Fronteira ibero-americana e miscigenação
}

\section{SÍLVIO MARCUS DE SOUZA CORREA*}

Resumo: $O$ presente artigo tem por fim abordar a miscigenação na formação social do espaço fronteiriço de Rio Pardo, Rio Grande do Sul, Brasil, entre 1750 e 1850, destacando a importância do contingente de mestiços no processo de povoamento do "continente".

Abstract: The following article aims to propose a polygenetic version on the social formation of the borderline space of Rio Pardo, Rio Grande do Sul, Brazil, between 1750 and 1850, highlighting its relevance of the contingent of mestizos in the process of populating the "continent".

Palavras-chave: Mestiçagem. Fronteira. Rio Pardo.

Key words: "Mestizoing". Frontier. Rio Pardo.

\section{Considerações preliminares sobre a historiografia regional da mestiçagem}

A etno-história e a história urbana permitem uma releitura sobre temas já enfocados pela historiografia regional. No Rio Grande do Sul, a mestiçagem e a genealogia do gaúcho foram temas presentes já desde a "construção do discurso historiográfico

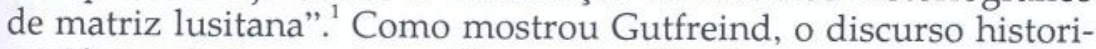
ográfico sul-rio-grandense já com Aurélio Porto sugere uma versão familiar e lusitana para o povoamento do Rio Grande do Sul. Souza Docca torna esta versão mais convincente, sendo que Othe-

* PhD pela Westfälische Wilhelms-Universität de Münster (Alemanha) e Professor do Departamento de História e Geografia e do Programa de Pós-Graduação em Desenvolvimento Regional da Universidade de Santa Cruz do Sul (UNISC).

Sobre o ciclo historiográfico lusitano, ver: GUTFREIND, Ieda. A Historiografia RioGrandense. Porto Alegre: Editora da Universidade (UFRGS), 1992. 
lo Rosa expande e aprofunda a matriz lusitana,120, que teria em Moysés Vellinho o seu aprimoramento literário e o desfecho deste "círculo historiográfico".

Para esta historiografia de matriz lusitana, a miscigenação com os indígenas fora inexpressiva no Rio Grande do Sul, pois os povoadores açorianos vieram com as famílias, enquanto que na região platina teriam vindo quase que apenas homens, redundando numa grande mestiçagem com o indígena e com o negro. ${ }^{3}$ Esta tese contra o hibridismo étnico da formação sul-rio-grandense encontrou ainda eco em artigo da década de oitenta. ${ }^{4}$ Compartilhando da tese de que não houve miscigenação, defendida também por Pedro Augusto Mentz Ribeiro, Pedro Ignácio Schmitz e José Proença Brochado, José Hildebrando Dacanal afirma que "a miscigenação não houve. Houve um processo de dominação e progressiva eliminação [do indígena]". ${ }^{6}$ Como observou com acuidade o antropólogo Ruben Oliven, o autor de "a miscigenação que não houve" não trabalhou com dados novos de pesquisa que pudessem embasar suas afirmações e - assim como Moysés Vellinho - acabou negando um lugar para o índio e o mestiço na sociedade sul-rio-grandense.

As considerações destes antropólogos e historiadores não foram suficientes para superar a visão ainda em voga de que a sociedade sul-rio-grandense fora formada por alienígenas, principalmente açorianos, alemães, italianos e africanos, sendo que estes últimos tiveram sua importância negada até 1940. O percentual da população negra na sociedade sulina sempre foi, todavia, subestimada, e somente a partir da década de 1960 é que a sua expressão demográfica foi reconhecida. ${ }^{8}$

Com as decisivas contribuições da etno-história, não foram apenas os grupos africanos que foram alvo das novas pesquisas históricas, mas também os indígenas. Destaque para as linhas de

Gutfreind, op. cit., p.37.

Gutfreind, op. cit., p. 118.

DACANAL, José H. A miscigenação que não houve. In: DACANAL, J. \& GONZAGA, S. (orgs.). RS: cultura E ideologia. Porto Alegre: Mercado Aberto, 1980, p. 25-33.

5 Os ensaios dos referidos autores que rejeitam a tese da miscigenação encontram-se reunidos em O índio no Rio Grande do Sul - perspectivas (1975), publicado pelo Governo do Estado, por ocasião do Biênio da Colonização e Imigração.

Dacanal, op. cit., p. 32.

OLIVEN, Ruben. A invisibilidade social e simbólica do negro no Rio Grande do Sul. In: LEITE, Ilka B. Negros no Sul do Brasil. Invisibilidade e Territorialidade. Florianópolis: Letras Contemporâneas, 1996, p. 23.

- Marco importante para o reconhecimento da importância do contingente africano para a formação do Rio Grande do Sul foi a tese de doutorado Capitalismo e escravidão no Brasil Meridional, de Fernando Henrique Cardoso. 
pesquisa desenvolvidas principalmente nos cursos de PósGraduação em História da UNISINOS e da PUCRS. Dado interessante é o número expressivo de dissertações de mestrado sobre temáticas indianistas, que perfaz em torno de $30 \%$ da atual produção historiográfica sul-rio-grandense. $\mathrm{O}$ conflito étnico enfocado nesta produção historiográfica é, no entanto, aquele entre os indígenas e os ibéricos, cujo recorte temporal e espacial abarca as Missões Jesuíticas. Enfim, predominam as dissertações sobre os indígenas durante o período missioneiro e posteriormente aos tratados de Madri (1750) e de Santo Ildefonso (1777) em relação ao número reduzido da produção historiográfica sobre os conflitos étnicos envolvendo indígenas e imigrantes europeus em áreas de colonização durante o século XIX.

Após o grupo de historiadores de origem luso-brasileira, os teuto-brasileiros ocupam um lugar expressivo enquanto grupo de pesquisadores sobre questões indígenas. Este interesse pelas temáticas missioneiras é, portanto, uma outra tendência atual na historiografia sul-rio-grandense. Superando a diatribe entre Moysés Vellinho e Mansueto Bernardi, que provocou a discussão sobre o pertencimento ou não do período missioneiro à história do Rio Grande do Sul, ${ }^{9}$ esta tendência revela-se como um atrativo àqueles pesquisadores que buscam um tema (indianista), sobre o qual tenta-se estabelecer a tão sonhada imparcialidade. Essa ilusória imparcialidade pode ser, portanto, uma das explicações para o expressivo número de dissertações sobre temáticas indianistas de autores teuto-brasileiros. Cabe ainda salientar que o franco processo de industrialização ocorrido durante os séculos XIX e XX nas regiões de imigração e colonização do estado também contribuiu para um certo romantismo extemporâneo desta geração de pesquisadores, cujo fascínio pelo "bom selvagem" está relacionado com uma autocrítica desta geração urbana ao seu próprio processo civilizatório.

Mas se a população indígena do Brasil meridional tem sua história recentemente habilitada, especialmente o período missioneiro do século XVII e XVIII e das reservas indígenas do século $X X$, o Oitocentos permanece como um hiato obscuro no que concerne aos estudos etnográficos ou etno-históricos. ${ }^{10} \mathrm{Um}$ dos motivos desta lacuna é a falta de estudos sobre a miscigenação no Rio Grande do Sul. É válido lembrar que durante o século XIX ocorre

\footnotetext{
Sobre esta querela intelectual, ver Gutfreind, op. cit., p. 85 e seguintes.

Os cursos de Pós-Graduação da PUCRS e da UNISINOS destacam-se no que tange à pesquisa sobre a história ameríndia no Rio Grande do Sul, bem como pela suas interfaces com a arqueologia, etnologia e antropologia.
} 
justamente um vertiginoso decréscimo demográfico da população indígena.

Apesar das copiosas referências à presença do negro e do indígena na vida cotidiana do Brasil meridional, bem como à sua participação nas guerras entre os ibéricos, a miscigenação sempre foi subestimada pela historiografia sul-rio-grandense. A colonização por casais açorianos e, posteriormente, por colonos e imigrantes alemães e italianos corrobora para a versão do povoamento familiar do Rio Grande do Sul. Apesar da composição multiétnica da população meridional, o predomínio de relações endogâmicas credita a monogenia da formação étnica de localidades como Rio Pardo. Porém, a exogamia infligida, sobretudo pelo europeu colonizador sobre os grupos étnicos subalternos, foi igualmente prolífera.

Considerando a importância da colonização forçada dirigida pela coroa de Portugal, especialmente nas áreas de fronteira do seu império, fica difícil entender a aparente negligência com o povoamento, através do degredo e do exílio, no extremo sul da América portuguesa, pois como concluiu Timothy Coates, "o uso de áreas recém-conquistadas ou descobertas é outro aspecto do processo de colonização português. Entre os seus outros traços culturais, os portugueses levaram o seu sistema judicial consigo para o ultramar e converteram rapidamente novos territórios a um velho sistema de exílio". "Tal prática começou não apenas no norte da África, como nas ilhas atlânticas. Em 1453, por exemplo, a Coroa projetava povoar a ilha de São Miguel (Açores) com criminosos, transformando degredados em colonizadores.

Em meados do século XVII, as autoridades lusitanas mudam a política de povoamento das colônias ultramarinas. A política anterior, que visava a "utilização" de criminosos, prostitutas, órfãos e de outros indivíduos solteiros, cedeu à colonização espontânea de famílias já constituídas. As primeiras experiências ocorreram na África portuguesa em 1635, 1651 e 1678-79, sendo que para o Brasil cinqüenta famílias açorianas de Santa Maria chegaram ao Maranhão em 1647 e dois anos depois desembarcaram mais cem famílias destes insulares em São Luís. Para a Colônia de Sacramento, 294 pessoas, na sua maior parte casais, foram reunidas em 1722 para deixar as ilhas do Pico e de São Jorge no arquipélago atlânti-

"Sobre a política lusitana de povoamento, ver: COATES, Timothy. Degredados e órfãs: Colonização dirigida pela coroa no império português. 1550-1755. Lisboa: Comissão Nacional para as Comemorações dos Descobrimentos Portugueses, 1998, p. 112.

12 VERLINDEN, Charles. The Beginnings of Modern Colonization. New York: Cornell University Press, 1970, p. 222-223. 
co. Em 1754, 500 pessoas da Madeira rumaram para Santa Catarina. ${ }^{13} \mathrm{O}$ extremo sul da América portuguesa teria sido, portanto, alvo da nova política de povoamento da Coroa portuguesa, de caráter espontâneo e familiar. Isto não significa que banimento e desterro não continuassem enquanto prática de colonização compulsória no Além-mar. É válido lembrar que desde o século XVI o Brasil era destino de muitos degredados, sendo que em 1629, o Desembargo do Paço comunica à Coroa que cerca de 10.000 condenados vagueiam livremente pelo Brasil.

As guerras no extremo sul da América portuguesa serviram para o recrutamento de muitos destes elementos marginais da sociedade colonial. A composição dos regimentos reinóis, paulistas, mineiros e cariocas à época da restauração de Rio Grande (1776) denota a presença destes out-siders. Nas memórias de sua expedição no sul do Brasil, o tenente-general João Henrique de Böhm faz menção inclusive a desertores e ladrões. ${ }^{15}$

\section{Monogenia versus poligenia}

Para Rio Pardo, a historiografia sul-rio-grandense aponta para uma colonização açoriana como base da sua formação social. A ênfase dada pelos historiadores diletantes dos meados do século XX para a influência açoriana redundou numa versão quase monogenética da formação étnica de Rio Pardo. ${ }^{16}$ Gilberto Freyre, em suas notas impressionistas sobre a arquitetura pretensamente açoriana do Rio Grande do Sul, já alertava que a arquitetura meridional, em relação àquela setentrional do país, tem peculiaridades mínimas, "sendo mais numerosas e evidentes as semelhanças dos sobrados do Sul com os sobrados do Norte e das demais regiões brasileiras em que esse tipo de arquitetura floresceu com caracte-

13 Coates, op. cit., p. 270-273. Para maiores informações sobre a colonização de ilhéus da Madeira para o Brasil, ver: Colonização do Brasil por Madeirenses. In: Arquivo Histórico da Madeira 5:1, 1937. O volume II (1932) deste mesmo Arquivo refere-se a dois livros de registros para o Brasil de casais e outros em 1747 e 1751 . Também ver: DONOVAN, Bill. The politics of immigration to eighteenth century Brazil: Azorean Migrants to Santa Catarina. Lisboa: Itinerário XVI, 1992, p. 35-36.

Coates, op. cit., p.174.

15 BÖHM, João Henrique de. Mémoires relatifs à 1 Expedition au Rio Grande. In: Anais do Simpósio Comemorativo do Bicentenário da Restauração do Rio Grande (1776-1976). Rio de Janeiro: Instituto Histórico e Geográfico Brasileiro/Instituto de Geografia e História Militar do Brasil, 1979, p. 194.

${ }^{16}$ Sobre a influência açoriana no sul do Brasil, ver: BORGES FORTES, João. Os casais açorianos. Presença lusa na formação sul-rio-grandense. 2. ed. Porto Alegre: Martins
Livreiro, 1978. 
rísticos nitidamente portugueses". ${ }^{17}$ Moacyr Flores aponta também para uma atribuição demasiada da influência açoriana, desprovida de sustentação empírica. Segundo ele, o fluxo açoriano foi pequeno e de curta duração, sendo a maioria dos colonizadores reinóis do continente e brasileiros de diversas províncias.

A leitura dos relatos de alguns viajantes que estiveram em Rio Pardo na primeira metade do século XIX permite inferir que sua arquitetura urbana deve mais aos comerciantes minhotos do que aos colonos açorianos. Saint-Hillaire relata que "a vila é inteiramente nova" e que aqueles estabelecidos há menos de trinta anos afirmam que antes "só se viam choupanas na localidade". ${ }^{19}$ Ao descrever algumas casas de Rio Pardo, o ilustre botânico francês se refere principalmente àquelas assobradadas, em grande número, as quais majoritariamente anunciam abastança com suas sacadas envidraçadas. ${ }^{20}$ Arsène Isabelle também menciona as casas novas com "elegantes janelas arqueadas, de dois batentes e grandes quadrados diversamente talhados". ${ }^{21}$ Este elemento decorativo da arquitetura urbana sulina também foi alvo da arguta observação de Freyre: [no Rio Grande do Sul] "a arte da vidraça em madeira ornamentada ou do caixilho teve a sua expressão artística mais rica, merecendo por si só um estudo paciente. Estudo que, acompanhado de minuciosa documentação fotográfica, colocaria sob os nossos olhos uma variedade de rendilhados de madeira utilizados como caixilhos de vidraças de janelas e de portas". ${ }^{22}$ Este detalhe refinado no estilo arquitetônico português não é absolutamente herança insular. Trata-se de uma arquitetura continental com evidente influência mourisca trazida principalmente pelos comerciantes e funcionários portugueses.

As observações dos viajantes sobre a arquitetura urbana de Rio Pardo revelam a existência de vários grupos e subgrupos étnicos e sociais. Arsène Isabelle relata que à primeira vista "Rio Pardo é uma cidade recente, pois há tantas construções novas, mas avançando do lado de sudeste ou do porto, reconhece-se bem depressa

17 FREYRE, Gilberto. Sugestões para o estudo histórico-social do sobrado no Rio Grande do Sul. Província de São Pedro. Porto Alegre: Edição Livraria do Globo, 1946, p. 10.

16 FLORES, Moacyr. História do Rio Grande do Sul. Porto Alegre: Nova Dimensão, $3^{\text {a ed., }}$ 1990 , p. 43.

19 SAINT-HILLAIRE, Auguste. Viagem ao Rio Grande do Sul. Belo Horizonte/São Paulo: Ed.Itatiaia/USP, 1974, p. 192.

20 Saint-Hillaire, op. cit., p. 193.

${ }^{21}$ ISABELLE, Arsène. Viagem ao Rio Grande do Sul. Porto Alegre: Martins Livreiro, 1983, p. 52.

22 Freyre, op. cit., p. 11. 
que é antiga, à vista das casas velhas e enfumaçadas, ainda guarnecidas de rótulas com grades de pau". ${ }^{23}$ Ainda em seu relato, Isabelle também menciona que "os principais comerciantes se acham precisamente na entrada, do lado oeste; é a cidade nova". ${ }^{24} \mathrm{Nico}-$ lau Dreys, ao referir-se à rua de Santo Anjo, escreve que "ela forma, por sua disposição particular, como um bairro separado, onde residem os principais negociantes em proporções com a população do país". ${ }^{25}$ Saint-Hillaire, por sua vez, já havia mencionado que "o comércio está quase inteiramente em mãos dos europeus, a maior parte sem educação e sem cultura, dos quais vários começaram como marinheiros, não sabendo ler nem escrever, e que, apesar de inferiores aos americanos em espírito e inteligência, sabem enriquecer-se melhor porque pensando sempre no futuro, economizam e tiram proveito da liberdade dos habitantes do país". ${ }^{26}$ Ainda com relação aos comerciantes portugueses, Saint-Hilaire comenta que "quando tais homens chegam de Portugal são de humildade extrema; mas tornando-se ricos esquecem sua baixa origem, tornam-se arrogantes e afetam desprezar os americanos, donde o ódio destes contra os europeus". ${ }^{27}$ Considerando as observações dos viajantes supracitados, pode-se inferir uma expansão física da vila de Rio Pardo, a qual acusa uma certa segregação social do espaço urbano, marcado por clivagens étnicas.

Quando Saint-Hilaire menciona a triticultura nos arredores de Rio Pardo, localiza-se então a presença lusitana de insulares no campo. ${ }^{28}$ Porém, ela não domina econômica e demograficamente a paisagem rural. O mesmo viajante escreve que "o couro e o trigo constituem os principais gêneros de exportação desta cidade". Significa que ao lado do agricultor açoriano, tem-se o estancieiro reinol ou luso-brasileiro. A coexistência de dois modelos agropecuários revela não apenas a bicefalia da organização socioeconômica de Rio Pardo, como também a presença de diferentes grupos étnicos no meio rural. Considerando ainda o número de trabalhadores livres e escravos de origem indígena e africana, pode-se afirmar que, em Rio Pardo, a vila e o campo eram unidades complementares multi-étnicas.

Isabelle, op. cit., p. 51.

Idem.

${ }^{25}$ DREYS, Nicolau. Notícia descritiva da Província do Rio Grande de S. Pedro do Sul. Porto Alegre: EDIPUCRS, 1990, p. 70.

Saint-Hillaire, op. cit., p. 193.

Idem.

Idem, p. 56.

Idem, 191. 
Conforme os mesmos viajantes, a paisagem humana de Rio Pardo era multicolor. Isabelle considera que "haveria motivos de sobra para o lápis de um caricaturista ou a pena de um escritor espirituoso neste lugar, onde tantas cenas grotescas se oferecem ao espectador atento. As roupas ou atavio dos viajantes nacionais e estrangeiros, a mistura de figuras negras, brancas, cor de cobre, de azeitona, e amulatadas; os remadores mestiços ou índios que acompanham tropas de animais [...]". ${ }^{30}$ Mas o exotismo racial, observado de forma hilária por Isabelle, pode remeter ao relato de seu compatriota Saint-Hilaire. "As índias dizem que se entregam aos homens de sua raça por dever, aos brancos por interesse e aos pretos por prazer." ${ }^{31}$ Embora ambos comentários estejam imbuídos de eurocentrismo, há uma relação de causa e efeito irrefutável, pois Isabelle não poderia contemplar aquela paleta multicolor sem a miscigenação proveniente dos tipos de intercurso sexual que servem ao comentário de Saint-Hilaire.

\section{A miscigenação no contexto beligerante}

Embora a vila de Rio Pardo tenha servido como uma espécie de depósito comercial, entre Porto Alegre e as povoações mais afastadas ao sul e ao oeste, ${ }^{32}$ ela tem sua origem relacionada à defesa da fronteira meridional da América portuguesa. Alvo estratégico para os interesses luso-brasileiros na região platina, Rio Pardo foi um posto militar fundamental para a expansão portuguesa naquela região. Dele resultou um pequeno povoado de origem étnica diversa. Como observam Vogt (e outros), "a função eminentemente militar de Rio Pardo, pelo menos nas três primeiras décadas iniciais, não impediu que se formasse, nas suas redondezas, um pequeno núcleo urbano composto inicialmente por militares e suas famílias, comerciantes, tropeiros de gado e colonos açorianos. Devido a sua importância militar e econômica, em março de 1769 , este povoado foi elevado à condição de Freguesia de Nossa Senhora do Rosário". ${ }^{33}$

Mas antes da formação do posto militar de Rio Pardo, os sucessivos ataques por parte dos castelhanos à Colônia do Sacramento levou a metrópole portuguesa a criar um Regimento de Dra-

Isabelle, op. cit., p. 52.

Saint-Hillaire, op. cit., p. 190.

Dreys, op. cit., p. 71.

3 VOGT et alii. Rio Pardo: Ascensão e Estagnação da Tranqueira Invicta. Revista Agora, v. 2, n. 1, Santa Cruz do Sul: UNISC, 1996, p. 56. 
gões naquela localidade às margens do Prata. Todavia, o embargo inimigo dificultava o acesso às pastagens das cercanias. Em 1737, Gomes Freire faz saber a Silva Paes da importância da organização de um corpo de Dragões em Rio Grande. Após o Tratado de Madri, o Regimento dos Dragões teve um papel de destaque na salvaguarda da fronteira, tornando Rio Pardo um baluarte inexpugnável, verdadeira "tranqueira", na expressão de Aurélio Porto e Sousa Doca. ${ }^{34}$ Segundo Vogt (e outros), em meados de 1751, Gomes Freire de Andrade, governador do Rio de Janeiro, tinha determinado "que na margem esquerda da confluência dos rios Pardo e Jacuí, no local hoje chamado Alto da Fortaleza, fosse criado um depósito de víveres e munição. No ano seguinte, em virtude da função estratégica para a defesa dos interesses lusos no Sul, os portugueses aí iniciaram a construção da Fortaleza Jesus-MariaJosé para servir como local de aquartelamento das tropas lusas".

Mas não foi apenas o regimento dos Dragões responsável pela "tranqueira invicta" e pela expansão e anexação dos territórios da atual região oeste e noroeste do estado. Papel decisivo tiveram os diversos regimentos de outras províncias brasileiras e as milícias de mestiços que serviram junto aos Dragões, principalmente após a guerra de 1762, quando as fronteiras do Rio Grande recuaram das margens do Uruguai e do Rio da Prata, até São José do Norte e Rio Pardo. ${ }^{36}$

Devido ao contexto beligerante na fronteira, o predomínio do contingente masculino foi inevitável. Mas o próprio José da Silva Paes já teria introduzido mulheres do Rio de Janeiro no Rio Grande de São Pedro a fim de minimizar o problema. Como observou Guilhermino César, a referência a mulheres airadas aparece em vários documentos. Elas são às vezes chamadas de mozuelas. Assim lhes chama Silva Paes em 1738, ao comunicar ao seu sucessor, André Ribeiro Coutinho: "seguem 20 artilheiros, alguns recrutas para os Dragões, fora de 4 ou 5 casais e várias mozuelas, que vão aí buscar estado e aqui o tinham de desenvoltas". ${ }^{37}$ Com elas, o Bri-

34 Apud: REICHARDT, H. Canabarro. Rio Pardo na simbologia rio-grandense. In: Anais do Simpósio Comemorativo do Bicentenário da Restauração do Rio Grande (17761976). Rio de Janeiro: Instituto Histórico e Geográfico Brasileiro/Instituto de Geografia e História Militar do Brasil, v. 2, 1979, p. 609.

35 Vogt et al., op. cit., p. 55.

36 Sobre Rio Pardo e o Regimento dos Dragões, encontram-se três artigos nos Anais do Segundo Congresso de História e Geografia Sul-Rio-Grandense, realizado em 1937. São eles: "A formação do Regimento doe Dragões do Rio Grande", de J. C. Rego Monteiro; "A revolta dos Dragões do Rio Grande", de Walter Spalding; e "A formação dos Dragões e os primeiros Osórios do Rio Grande”, de Fernando Luiz Osório.

37 CÉSAR, Guilhermino. Primeiros cronistas do Rio Grande do Sul: 1605-1801. 2. ed. Porto Alegre: Ed. da Universidade (UFRGS), p. 128. 
gadeiro buscava resolver o déficit demográfico da região. Pode-se inferir também que esta medida era uma alternativa a certas práticas sexuais (prostituição, homofilia, zoofilia etc.) da população masculina, sobretudo soldados e milicianos.

O número superior de homens em áreas beligerantes também possibilitou um tipo de eventual poligamia, na qual vários homens usufruíam os favores sexuais de uma mulher. O tenentegeneral João Henrique de Böhm relata em sua carta de 22 de abril de 1778 o crime passional, cuja vítima foi o major José da Nóbrega. Por causa de uma índia, o major Nóbrega teria sido assassinado por alguns guardiões de gado, dos quais ela era amante. ${ }^{38}$ Neste homicídio, foram inculpados o capataz Francisco José e outros, sendo o delator um negro. Segundo o tenente-general de Böhm, o motivo do assassinato foi a usurpação dos préstimos sexuais da índia por parte do major Nóbrega que teria provocado os ciúmes de seus amantes. Já o negro delator provavelmente abriu a boca para livrar-se da acusação, uma vez que os criminosos estavam em vias de fugir. Vítima branca, adúltera índia, criminosos mestiços e delator negro, um caso de relação interétnica que seguramente não era exceção no teatro da guerra, a que o Rio Grande serviu muitas vezes de palco.

O intercurso sexual de homens brancos com mulheres índias era intenso na América hispânica e não haveria de ser diferente no lado lusitano. Em Assunção, Cabeza de Vaca teria recebido queixas dos índios agacês, que acusavam os espanhóis de arrebatar suas mulheres para os acampamentos militares. Aliás, o seu antecessor, Irala, havia praticado a poligamia, ao desposar várias filhas de caciques. Em suma, muitos cronistas da época da Conquista referem que, depois de 1550 , formigavam os mestiços de espanhóis com índias. ${ }^{39}$ Cabe perguntar por que o raptor das sabinas ameríndias teria sido apenas o espanhol? Os próprios filhos de índias, bandeirantes, tropeiros e milicianos vicentinos, mineiros e lagunenses reproduziram a tradição paterna dos seus progenitores portugueses nos ventres das índias de várias nações do Brasil meridional.

Entre tantos mestiços, filhos de "índia da terra", destaca-se o furriel Gabriel Ribeiro de Almeida. Ao terminar a incorporação

36 BÖHM, João Henrique de. Mémoires relatifs à l'Expedition au Rio Grande. In: Anais do Simpósio Comemorativo do Bicentenário da Restauração do Rio Grande (1776-1976). Rio de Janeiro: Instituto Histórico e Geográfico Brasileiro/Instituto de Geografia e História Militar do Brasil, 1979, p. 202-203.

39 ORNELLAS, Manoelito. Gaúchos e Beduínos. A origem étnica e a formação social do Rio Grande do Sul. Porto Alegre: Martins Livreiro, 1998, p. 12-13. 
dos Sete Povos das Missões (1801), Almeida foi promovido a tenente de milícias, e ao falecer já era capitão. A sua memória, escrita em 1806, oferece muitos elementos para conjeturar sobre as relações interétnicas naquela região híbrida em disputa pelas duas coroas ibéricas. O comandante da fronteira de Rio Pardo, tenentecoronel Patrício José Correia da Câmara, foi o supervisor desta conquista, cujos protagonistas principais foram dois mestiços, Gabriel Ribeiro de Almeida e Manuel dos Santos Pedroso, e um filho de açorianos, José Borges do Canto.

Segundo o proprietário de terras no vale do Rio Pardo Gabriel Ribeiro de Almeida, ele e José Borges do Canto, natural de Rio Pardo, conquistaram os Sete Povos das Missões com quarenta homens. O dito Canto era desertor, e durante muitos anos vivera entre espanhóis e portugueses naquela vasta campanha que Gabriel Ribeiro de Almeida chamou de "couto e refúgio dos criminosos de ambas as nações".40 Ora, os coutos eram localidades de asilo em Portugal. Tratava-se de um exílio dentro do próprio reino, utilizado desde o século XIV pela Coroa para povoar regiões fronteiriças que tinham déficit demográfico depois da Reconquista. $\mathrm{O}$ sistema de localidades de asilos (coutos) foi utilizado até a última década do século XVII e empregado também no Ultramar. ${ }^{41}$ Nesse sentido, é espantoso que um mestiço, filho de "índia da terra" conheça o vocábulo e o empregue corretamente ao se referir à área de fronteira entre os domínios de Espanha e Portugal na América do $\mathrm{Sul}^{42} \mathrm{O}$ uso deste vocábulo e a menção da existência de criminosos permitem inferir destarte que a política de povoamento espontâneo (com famílias insulares) no Brasil meridional não exclui a antiga prática de enviar às fronteiras do Império contingentes marginais do reino.

A clandestinidade, típica das áreas de fronteira, também atraiu os delinqüentes locais. José Borges do Canto foi um exemplo de descendente açoriano que incorporou os valores guerreiros da sociedade local, na qual a pilhagem e o contrabando eram atividades econômicas de bravos homens. "José do Canto, ora entrava na Capitania do Rio Grande de São Pedro, donde era natural, ora nas terras dos espanhóis a traficar contrabandos; em uma e outra parte

\footnotetext{
40 ALMEIDA, Gabriel Ribeiro. A Tomada dos Sete Povos das Missões (1801). In: CÉSAR, Guilhermino. Primeiros cronistas do Rio Grande do Sul: 1605-1801. 2. ed. Porto Alegre: Ed. da Universidade (UFRGS), 1981, p. 196-197.

${ }^{41}$ Sobre os coutos, ver: Coates, op. cit., p. 96-112.

42 Os coutos também foram utilizados em Portugal nas áreas de fronteira com a Espanha.
} 
passeava disfarçado, pois se tinha feito célebre com a sua vida extravagante e odiosa a ambas as nações".

A presença destes marginais não era sempre um estorvo às Coroas. Ambas recrutavam essa gente para pegar em armas em troca da anistia. Assim aconteceu com José do Canto, que se colocou ao serviço do comandante da fronteira de Rio Pardo, Patrício José Corrêa da Câmara. O episódio da tomada dos Sete Povos das Missões revela também outros elementos da composição interétnica das milícias lideradas tanto por espanhóis quanto por reinóis ou luso-brasileiros. Ambas são compostas majoritariamente por indígenas. Vindos do Paraguai e de outros povos além do Uruguai, os espanhóis contavam com várias e numerosas milícias, porém elas foram desbaratadas pelos milicianos de José do Canto e Gabriel Ribeiro de Almeida.

Como salienta Guilhermino César, o que motivou em particular a atuação dos três expedicionários José Borges do Canto, Gabriel Ribeiro de Almeida e Manuel dos Santos Pedroso na tomada dos Sete Povos das Missões foi justamente a preia ao gado, pois eram todos homens do campo já acostumados com a pilhagem e o contrabando de gado pela Campanha. ${ }^{45}$ É mister salientar que ao longo do século XVIII se intensificara o comércio de contrabando através da estrada de São Martinho, que ligava Santa Maria da Boca do Monte às Missões, ou pela rota da Encruzilhada, que do coração da Campanha conduzia a Rio Pardo. ${ }^{46}$

O comércio ilícito praticado por estancieiros e gaudérios, muitos do vale de Rio Pardo, também pode ser acompanhado através das proezas do major Rafael Pinto Bandeira, mencionadas pelo tenente-general João Henrique de Böhm sobre a incursão sobre Santa Tecla, rendimento de espanhóis, pilhagem de gado vacum e eqüinos.

"J'ai reçu de lettres du Rio Pardo: que le Major Rafael, se trouve déjà avec son Corps sur Sta. Thecla, ayant coupé les Espanhols et enlévés leur Bétail et chevaux, ce qui me fait espérer, qu'ils se rendront en peu:

43 Almeida, op. cit., p. 97.

44 Depois do primeiro confronto com uma tropa inimiga, José do Canto pediu para Almeida fazer parte do comando e direção daquela campanha, pois ele se confundia por não entender a língua daqueles índios. Mais tarde, Almeida também intervém junto aos trezentos índios, vindos até do Paraguai, sob o comando de cem espanhóis que foram capturados. Estes índios passariam para o lado dos "portugueses" e garantiriam o sucesso da empresa no assalto a São Miguel.

45 CÉSAR, Guilhermino. O contrabando no sul do Brasil. Caxias do Sul/Porto Alegre: UCS/EST, 1978, p. 54.

46. Idem, p. 45. 
Le Major Rafael dans sa lettre dit: qu'il marche avec 437 hommes, Trouppes et 180 Gauderios (qui est un nom plus honêt [sic] dont on se sert au lieu de celui de voleurs) des Espanhols, des Indiens et d'Esclaves, en tou avec 617 hommes et deux fauconneaux, parce que celà parût si joli au Gouverneur."

Além do saque, atrativo econômico principal dos homens de guerra, a passagem supracitada da carta de 11 de março 1776 de Böhm refere-se a uma pluralidade étnica do corpo militar, no qual espanhóis, índios, negros se somam aos portugueses e lusobrasileiros. Nota-se que o termo "gaudério" aparece como eufemismo de ladrão. Estes gaudérios tinham uma posição dúbia em relação aos estancieiros. Muitas vezes serviam a estes, como também poderiam representar seus concorrentes, sobretudo no que diz respeito ao comércio ilícito do gado vacum e cavalar. As $\mathrm{Me}$ mórias de Böhm oferecem uma passagem interessante neste sentido, na qual percebe-se a importância econômica dos gaudérios em Rio Pardo:

"Les Fermiers trouvant de grandes difficultés à fournir les viandes, je me vis obligé à consentir qu'on leurs cède les miliers de bétail que les Gaudérios de Rio Pardo emmenèrent sur la fin de l'Octobre, tirés des Vassaux de l'Espagne, comme j'ai rapporté dans ma lettre du 8 Novembre." 48

A importância bélica e econômica destes gaudérios, assim como a de homens como José Borges do Canto, Gabriel Ribeiro de Almeida e Rafael Pinto Bandeira, denota uma sociedade guerreira, na qual a miscigenação era tolerada. Porém, a miscigenação não pode ser vista de forma monolítica. Muitos mestiços, negros e índios eram tolerados na sociedade luso-brasileira local sob uma forte discriminação social. A discriminação racial e social poderia ser maior caso estes grupos fossem ainda "estrangeiros".

Em carta de 12 de setembro de 1777, o tenente-general de Böhm refere-se ao expressivo contingente de índios Minuanos que, sob a custódia do major Rafael Pinto Bandeira, foram introduzidos no território. João Henrique de Böhm faz saber que o grupo de Minuanos deveria se comportar como qualquer vassalo e súdito português. ${ }^{49} \mathrm{Na}$ fronteira, o fluxo e refluxo da vaga migratória de milicianos indígenas, desertores espanhóis e portugueses, negros fugidos e mestiços livres envolvidos com o contrabando e a pilhagem permite afirmar que Rio Pardo não foi para muitos um posto 
provisório. Como local de estacionamento de tropas e mercado importante do contrabando, Rio Pardo acabou tornando-se abrigo perpétuo para muitos homens e mulheres envolvidos (in)diretamente com as guerras entre os ibéricos em áreas fronteiriças sulamericanas.

Os voluntários dos regimentos de São Paulo, Minas Gerais, Rio de Janeiro e mesmo de Portugal também contribuíram para a multigênese da formação étnica e social de Rio Pardo. Apesar de ser irrefutável a sua participação na amálgama etno-social nas regiões de fronteira do extremo sul da América portuguesa de então, muitos destes milicianos eram mal vistos à época. A referência que João Henrique de Böhm faz da primeira coluna de mineiros ilustra não apenas sua composição étnica mista, como também a inquietação que tal orla suscitava:

"Le Gouverneur de St. Paul m'avise dans une lettre du 30 d'Avril, de l'arrivée de la première colonne des gens de Minas Gerais, et en fait une peinture capable de desanimer [sic] l'homme le plus resolû; vû l'impossibilité qu'un tel ramas de noirs, de blancs, de mulâtes, à pieds nuds, sans armes, sans discipline, puisse être de la moindre utilité, et ne pas causer la ruine du Païs où ils arrivent au lieu de le sauver." ${ }^{51}$

Mas as tropas de voluntários de outras províncias não causavam apenas inquietações concernentes à desestabilização da ordem e da segurança pública, como também problemas relativos à sua alimentação. $\mathrm{O}$ tenente-general de Böhm adverte que não tem meios para alimentar, vestir, armar, pagar e nem oficiais para disciplinar a coluna de Minas. ${ }^{52}$ Em sua carta de 5 de janeiro de 1776, ele solicita para Rio Pardo mais dois mil alqueires de farinha de mandioca, tendo em vista a chegada dos voluntários paulistas. ${ }^{53} \mathrm{~A}$ precária situação dos alojamentos, a alimentação frugal e, muitas vezes, insuficiente, a falta de materiais desde calçados até armas e o atraso dos soldos foram responsáveis pelos altos índices de deserção. Muitos destes voluntários, portanto, deixaram as colunas e foram sendo incorporados na população civil economicamente

50 Em suas memórias, o tenente-general de Böhm menciona cinqüenta combatentes paulistas que ficaram em solo sul-rio-grandense (p. 200), bem como três mineiros que voluntariamente não quiseram acompanhar seus pares na sumaca do mestre João Marcos Moreira (p. 209).

Idem, p. 172.

53. Idem, p. 90-91. 
através do trabalho (faina agrícola, atividades comerciais e outras) e socialmente através da mancebia ou do casamento. ${ }^{54}$

O contexto beligerante também serviu para a diluição das famílias açorianas parcialmente bem estruturadas. As guerras comprometeram a estabilidade do mercado regional e os ganhos com a agricultura e a pecuária oscilaram drasticamente. Aliás, o expressivo contingente de tropas estacionadas em Rio Pardo foi um dos motivos da ruína de muitos camponeses. A migração (in)voluntária das famílias camponesas e o engajamento compulsório de seus filhos no front concorreram para a diminuição da endogamia entre os ilhéus, permitindo assim uma paulatina miscigenação luso-brasileira. De Böhm lamenta a vulnerabilidade dos açorianos frente à situação de guerra, cujas medidas arbitrárias os desencorajavam.

"Ces hommes [os açorianos] feroient de grands Progrès dans l'Agriculture et enrichiroient le Païs, si on les enseignoit et animoit. Mais, en s'assurant de leur Récolte pour compte du Roi, qui n'en fait rien, en mettant leurs fils dans les Trouppes, contraire aus formelles Assurances du Souverain, et à les obligeant à des Corvées de toute espèce, ils sont fort découragés." 55

O desânimo não era apanágio dos insulares. Alguns comerciantes sofreram perdas significativas em seus negócios com o constante estado beligerante e desanimados partiram de Rio Pardo. O viajante e comerciante, Nicolau Dreys, apontou a guerra civil, desencadeada em 1835, como responsável pelo "luto e a desolação" que afetou o florescente comércio rio-pardense. ${ }^{56}$ Depois de uma década de guerra civil, a guerra contra a república argentina de Rosas fez novamente de Rio Pardo um posto estacionário das tropas militares. Além das tropas brasileiras, os batalhões de mercenários alemães estiveram na cidade, onde muitos permaneceram por meses e alguns para sempre na nova colônia de Santa Cruz, à época sob a jurisdição de Rio Pardo.

Segundo as memórias do Brummer J. J. Schnack, em Rio Pardo alguns destes mercenários faziam uma espécie de serviço de guarnição, cujo recebimento não era mais em espécie, como foi durante a permanência dos mercenários na Colônia de Sacramen-

54 Exemplo desta incorporação sOcioeconômica de combatentes foi o caso de muitos mercenários alemães (Brummer), cujos relatos são abundantes. Ver: Memórias de Brummer (Cristóvão Lenz, Henrique Schäfer e Jorge Julio Schnack). Porto Alegre: EST, 1997.

55 Böhm, op. cit., p. 23.

Dreys, op. cit., p. 70. 
to, mas em dinheiro. ${ }^{57}$ Além da tropa de mercenários alemães, outros militares estrangeiros estiveram em Rio Pardo nos meados do século XIX. O general inglês Caldwell e o major suíço Resin são alguns exemplos, sendo que este último foi o comandante do Batalhão de Infantaria Alemão sediado em Rio Pardo, em 1852. Devese salientar que esta cidade era ponto estratégico militar, de onde partia toda a comunicação para as fronteiras sul e oeste.

Dos mercenários alemães aquartelados em Rio Pardo, alguns foram incorporados voluntariamente à Artilharia, outros receberam terras na Colônia Provincial de Santa Cruz e o restante foi para Porto Alegre, sendo que alguns regressaram à Alemanha. ${ }^{58} \mathrm{O}$ caso Brummer é, portanto, um outro bom exemplo histórico da miscigenação promovida pelas armas em Rio Pardo. E se o binômio armas e amas pode parecer uma especulação sem base empírica, cabe citar uma passagem das memórias do Brummer Schnack:

"Em uma campanha brasileira como esta, muito 'João' leva a sua 'Maria', o que não é proibido nas instâncias superiores. Do lado de cá do rio de la Plata isto não constituiu empecilho, pois o campo é amplo e havia espaço para todos. Mas a situação mudou quando fomos embarcados em Colônia. Com espaço apertado, as Marias tiveram de ficar para trás. Até a batalha de Maron [Monte Caseros] uma parte do Batalhão brasileiro ficou do lado de cá, mas no dia posterior ao combate foram também embarcados e as Marias tiveram de ficar. Todas elas foram então reunidas e abrigadas em um acampamento de barracas, onde tinham de ser vigiadas. Como não havia tropas nacionais disponíveis para esse fim, a Infantaria e a Artilharia dos alemães eram suficientemente bons para isto. Também eu fui designado para uma guarda de 24 horas, mas não recordo as instruções de guarda., ${ }^{59}$

Embora haja poucas referências documentais sobre a vida sexual no front, a passagem supracitada permite inferir um contingente significativo de mulheres junto às tropas brasileiras que além dos préstimos sexuais, auxiliavam nos serviços de enfermagem etc. Estacionados em Rio Pardo, muitos militares e milicianos tiveram a oportunidade de conhecer mulheres e raparigas com as quais tiveram relações efêmeras ou mesmo duradouras, pois a estada naquela cidade não era de toda absorvida pelos exercícios militares. Uma outra passagem das memórias do Brummer Sch-

${ }_{55}^{57}$ SCHNACK, Júlio. Memórias de Brummer. Porto Alegre: EST, 1997, p. 96.

58 Idem, p. 97.

59 Idem, p. 92 
nack demonstra como os militares gozavam de tempo para vaguear e fazer amizades.

"Henrique Schäfer e eu servimos na 4 a Cia. do mesmo Batalhão que fora tratado em Hamburgo para o Brasil e comungamos dos mesmos acontecimentos da incomum e extraordinária viagem de Hamburgo até Rio Pardo, onde deixamos o serviço militar. Conhecemonos melhor e nossa amizade se fortaleceu em Rio Pardo, onde permanecemos por quatro meses antes de nossa baixa. Lá tivemos pouco serviço e normalmente as tardes estavam livres. Foi então que muitas vezes passeávamos por ruelas transversais (não havia casas, mas muros de ambos os lados e calçadas) e em longas horas de conversa confiávamos vivências mútuas, fazíamos planos para o futuro, conversávamos sobre política e filosofávamos como dois jovens de 20-22 anos sabem fazer. Assunto não faltava neste mundo novo, onde tudo nos parecia diferente e maravilhoso. E o fato de normalmente termos opiniões diferentes, que defendíamos com ardor, assegurava a continuidade de nossas conversas."

Se os dois jovens alemães dispensavam o seu tempo livre com diálogos sobre "política e filosofia", alguns tinham provavelmente outras predileções. $\mathrm{O}$ jogo, a bebida e a prostituição provavelmente ocuparam as horas de folga de muitos aquartelados em Rio Pardo. De qualquer forma, as relações inter-étnicas intra ou extramuros do quartel eram cotidianas na vida dos militares estacionados em Rio Pardo. Desde os tempos dos Dragões até dos Brummer, isto é, dos meados do século XVIII até meados do século XIX, a cidade de Rio Pardo serviu não apenas como posto militar e de empório, mas como locus matrix da miscigenação, cuja importância para o povoamento do "continente" ainda espera por uma avaliação acurada por parte da nova historiografia sul-riograndense.

\section{A miscigenação no contexto comercial}

Se a condição fronteiriça de Rio Pardo foi importante para a formação de um posto militar em permanente atividade que serviu como elemento catalisador da miscigenação, as relações interétnicas tiveram também o comércio como vetor. A relação entre postos militar e comercial em Rio Pardo pode ser entendida segundo a lógica apontada por Macedo: "Sobrevivência, defesa e abrigo, três aspectos da instalação comunitária para o estabeleci- 
mento de formações humanas duráveis, que serão logo seguidas pelas unidades ligadas ao trabalho, transporte e comércio." ${ }^{61}$ Segundo dados apresentados por Macedo, o núcleo urbano de Rio Pardo tinha, em 1780, 2.374 pessoas. Já em 1803 este número cresceu para 3.739 habitantes. Em 1807, era de 7.032 pessoas, incluindo índios, libertos e cativos. No mesmo período, havia em Porto Alegre 4.702 pessoas, e em Rio Grande, 10.817. Portanto, Rio Pardo detinha maior concentração populacional que Porto Alegre, o que propiciou o desenvolvimento de várias atividades, entre elas o comércio. $^{62}$

Com a abertura dos portos para as nações amigas, um significativo aumento na circulação de mercadorias ocorreu através do porto de Rio Grande para Rio Pardo. Comerciantes de grande e pequeno trato, especialmente portugueses, circularam igualmente pelo Brasil meridional e alguns chegaram a fixar residência em Rio Pardo. A contribuição de Gauer permite inferir a expressiva presença destes comerciantes naquela cidade. ${ }^{63}$ Mas não é, em geral, a atividade comercial que os fixara naquela localidade e sim o devir estancieiro e as alianças matrimoniais.

Considerando a origem dos comerciantes (Laguna, São Paulo, Rio de Janeiro, Braga, Porto) e a origem local de suas mulheres, Souza sugere que os casamentos com mulheres locais eram uma das formas de inserção social dos comerciantes estrangeiros em Rio Pardo. ${ }^{64}$ Casamento com filhas de militares, principalmente os mais graduados, era estratégia de ascensão social e aquisição de capital simbólico por parte de alguns varões de famílias de comerciantes. Embora a contribuição de Souza seja importante para demonstrar como alguns laços matrimoniais implicavam relações entre diferentes grupos étnicos e sociais em Rio Pardo, ela é uma exceção à regra. Avessa aos estudos genealógicos, a nova historiografia não contempla análises demográficas e a história social proposta apresenta uma lacuna ao tratar en passant fenômenos sociológicos como a mobilidade social através de alianças matrimoniais.

61 MACEDO, Francisco R. Arquitetura Luso-Brasileira. In: WEIMER, Günter (org.). A Arquitetura no Rio Grande do Sul. Porto Alegre: Mercado Aberto, 1987, p. 34.

62 SOUZA, Sabrina Silva de. Comerciantes em Rio Pardo-RS: Atuações comerciais e relações sociais (1800-1835). Porto Alegre: PUCRS, 1998 (dissertação de mestrado), p. 30-31.

63 SOUZA, Sabrina Silva de. Os comerciantes em Rio Pardo no início do século XIX e o trinômio espaço/tempo/velocidade. In: SILVA, Mozart L. (org.). Tempo/História. Porto Alegre: EDIPUCRS, 1998. 
Algumas alianças são muito ilustrativas em termos sociológicos. Manuel José Ferreira de Faria era natural da freguesia de Santa Maria de Faria, termo de Barcelos, do Arcebispado de Braga, cujos pais eram da mesma freguesia. Em 1806, Manuel J. F. Faria casou com Maria Esméria Pires, natural de Rio Pardo, filha do Tenente Antônio Simões Pires e de sua mulher Maria do Carmo. Manuel J. F. Faria ao casar-se com Maria Esméria entrava para a família de Mateus Simões Pires, um grande e rico proprietário de terras. Faria contou com o apoio de seu sogro nos negócios, pois este também era comerciante em Rio Pardo.

Em 1809, João Pereira Monteiro, filho de pais naturais da freguesia de Nossa Senhora da Vitória do Bispado do Porto, casou-se com Angélica Rosa de Oliveira, filha do Capitão Francisco de Oliveira Porto e de sua falecida esposa Dona Maria Francisca da Silveira, natural de Rio Pardo. Monteiro e seu sogro, juntamente com Alexandre de Abreu Vale, também casado com uma filha de Porto, organizaram, em 1815, uma sociedade comercial. ${ }^{66}$

As alianças matrimoniais e comerciais atendiam a certos interesses no seio da elite tradicional e permitiam também a inclusão de uma incipiente burguesia comercial. Como estratégia de reprodução social, os casamentos intragrupo se mantinham como, por exemplo, entre as famílias de alguns militares. O Guarda Mor Manuel Pedroso de Albuquerque, filho legítimo do Tenente João Pedroso de Albuquerque (de São Paulo) e de Dona Maria Benedita de Albuquerque (de Rio Pardo), casou-se em 1821, com Dona Mafalda Sinforoza de Figueiredo Menna Barreto, filha legítima do Marechal João de Deus Menna Barreto e de sua mulher Dona Rita Bernarda Cortês de Figueiredo Menna. ${ }^{67}$

A miscigenação ocorria também entre comerciantes pobres. Inclusive, seus estabelecimentos comerciais permitiam certas relações interétnicas, como descreve Souza:

"As tabernas e os botequins eram lugares onde predominavam o comércio de bebidas alcoólicas. Acompanhando-as estavam o jogo e muitas vezes a prostituição de mulheres, fossem elas escravas ou brancas. Eram ambientes freqüentados por indivíduos de condições de vida mais pobres, como, por exemplo, escravos forros." ${ }^{68}$

Em 1831, o Juiz de Paz Vasco Pereira de Macedo solicitava, "a bem do sossego e da tranqüilidade", à Câmara Municipal de Rio

\footnotetext{
Idem, p. 172.

Idem, p. 173.

Idem, p. 173-174.
}

Souza, op. cit., p. 88. 
Pardo que interviesse no botequim do pardo Caetano, cuja licença foi retirada junto à Câmara pela sua mulher. Como observa com acuidade Souza, as evidências indicam que Caetano era pardo forro, pois se fosse branco ele mesmo tiraria a licença para o seu botequim. O mestiço Caetano e sua mulher, provavelmente branca, são exemplos da união entre categorias sociais e étnicas diferentes, cuja atividade econômica (comércio) fomentara a interação da mocidade branca com cativos negros e pardos num modesto empório de Rio Pardo.

A partir desses casos esparsos de relações étnicas e sociais através de alianças matrimoniais pode-se inferir que a miscigenação ocorreu entre todos os segmentos da sociedade de Rio Pardo. Algumas delas permitiram uma ascensão social, embora os estudos mais recentes de Osório sobre as redes familiares e mercantis no Rio Grande do Sul durante a segunda metade do século XVIII e primeiras décadas do século XIX acusam uma dificuldade em conjeturar sobre a mobilidade social entre comerciantes, estancieiros e militares para Rio Pardo. ${ }^{69}$ Em muitos casos, comerciantes e militares formaram respectivamente uma fração da elite rio-pardense, mas é o matrimônio (= união entre famílias) que consagrava o status adquirido dos indivíduos, pois o seu status atribuído é, geralmente, vinculado à sua origem familiar. Ao casar com pessoa da mesma origem social, ratificava-se o status atribuído. Já o casamento com pessoa de outra origem social fazia predominar o status adquirido sobre o da origem social. Em alguns casos, o status adquirido se dava exclusivamente pelo matrimônio.

Em termos genéricos, pode-se propor a seguinte tabela de possibilidades de relações matrimoniais entre grupos sociais e étnicos, embora para algumas delas (como as relações "AL" e "LA") nenhum registro histórico tenha sido encontrado. Pardo.

Relações matrimoniais entre grupos sociais e étnicos em Rio

OSORIO, Helen. Comerciantes do Rio Grande de São Pedro: formação, recrutamento e negócios de um grupo mercantil da América Portuguesa. Revista Brasileira de História, São Paulo, v. 20, n. 39, 2000, p. 115-134. 


\begin{tabular}{|c|c|c|c|c|c|c|c|c|c|c|c|c|c|}
\hline \multirow[b]{2}{*}{$\bullet$} & \multicolumn{3}{|c|}{$\begin{array}{l}\text { Estamentos } \\
\text { superiores }\end{array}$} & \multicolumn{3}{|c|}{$\begin{array}{l}\text { Estamentos } \\
\text { intermediários } \\
\text { superiores }\end{array}$} & \multicolumn{3}{|c|}{$\begin{array}{l}\text { Estamentos } \\
\text { intermediários } \\
\text { inferiores }\end{array}$} & \multicolumn{3}{|c|}{$\begin{array}{l}\text { Estamentos } \\
\text { inferiores }\end{array}$} & \\
\hline & A & B & C & $D$ & $\mathrm{E}$ & $\mathrm{F}$ & G & $\mathrm{H}$ & 1 & $\mathrm{~J}$ & $\mathrm{~K}$ & $\mathrm{~L}$ & \\
\hline $\mathrm{A}$ & $X X$ & $A B$ & $A C$ & $A D$ & $\mathrm{AE}$ & AF & $A G$ & $\mathrm{AH}$ & $\mathrm{Al}$ & AJ & $\mathrm{AK}$ & $\mathrm{AL}$ & A \\
\hline B & BA & $X X$ & $B C$ & $B D$ & $\mathrm{BE}$ & $\mathrm{BF}$ & $B G$ & $\mathrm{BH}$ & $\mathrm{BI}$ & BJ & BK & $B L$ & $B$ \\
\hline C & $\mathrm{CA}$ & $\mathrm{CB}$ & $X X$ & $C D$ & $\mathrm{CE}$ & $\mathrm{CF}$ & $C G$ & $\mathrm{CH}$ & $\mathrm{Cl}$ & $\mathrm{CJ}$ & $\mathrm{CK}$ & $\mathrm{CL}$ & C \\
\hline D & DA & DB & $\mathrm{DC}$ & $X X$ & $\mathrm{DE}$ & DF & $D G$ & $\mathrm{DH}$ & DI & DJ & DK & $\mathrm{DL}$ & $D$ \\
\hline $\mathrm{E}$ & EA & EB & EC & ED & $\mathrm{XX}$ & EF & EG & $\mathrm{EH}$ & El & EJ & EK & $\mathrm{EL}$ & $E$ \\
\hline $\mathrm{F}$ & FA & FB & $\mathrm{FC}$ & FD & $\mathrm{FE}$ & $X X$ & $F G$ & $\mathrm{FH}$ & $\mathrm{FI}$ & FJ & FK & $\mathrm{FL}$ & $\mathrm{F}$ \\
\hline G & GA & GB & GC & GD & $\mathrm{GE}$ & GF & $X X$ & $\mathrm{GH}$ & $\mathrm{Gl}$ & GJ & GK & GL & $\mathrm{G}$ \\
\hline $\mathrm{H}$ & $\mathrm{HA}$ & $\mathrm{HB}$ & $\mathrm{HC}$ & $\mathrm{HD}$ & $\mathrm{HE}$ & $\mathrm{HF}$ & $\mathrm{HG}$ & $\mathrm{XX}$ & $\mathrm{HI}$ & $\mathrm{HJ}$ & $\mathrm{HK}$ & $\mathrm{HL}$ & $\mathrm{H}$ \\
\hline I & IA & IB & IC & ID & $\mathrm{IE}$ & IF & IG & $\mathrm{IH}$ & $\mathrm{XX}$ & IJ & IK & IL & 1 \\
\hline $\mathrm{J}$ & $\mathrm{JA}$ & $\mathrm{JB}$ & $\mathrm{JC}$ & $\mathrm{JD}$ & $\mathrm{JE}$ & $\mathrm{JF}$ & JG & $\mathrm{JH}$ & JI & $\mathrm{XX}$ & $\mathrm{JK}$ & $\mathrm{JL}$ & $\mathrm{J}$ \\
\hline $\mathrm{K}$ & $\mathrm{KA}$ & $\mathrm{KB}$ & $\mathrm{KC}$ & $K D$ & $\mathrm{KE}$ & $\mathrm{KF}$ & $K G$ & $\mathrm{KH}$ & $\mathrm{KI}$ & $\mathrm{KJ}$ & $X X X$ & $\mathrm{KL}$ & $\mathrm{K}$ \\
\hline \multirow[t]{2}{*}{$\mathrm{L}$} & LA & LB & LC & LD & LE & LF & LG & $\mathrm{LH}$ & $\mathrm{LI}$ & LJ & LK & $X X X$ & $L$ \\
\hline & A & $B$ & C & $D$ & $E$ & $\mathrm{~F}$ & $\mathrm{G}$ & $\mathrm{H}$ & 1 & $\mathrm{~J}$ & $K$ & L & $\bullet$ \\
\hline
\end{tabular}

A) português proprietário

B) brasileiro proprietário

C) estrangeiro proprietário (francês, alemão...)

D) português não-proprietário

E) brasileiro não-proprietário

F) estrangeiro não-proprietário
G) indigena livre

H) pardo livre

I) negro livre

J) indígena escravo

K) pardo escravo negro escravo

A averiguação empírica da diferente freqüência das relações matrimoniais entre grupos sociais e étnicos em Rio Pardo entre 1750 e 1850 poderia contribuir para uma história da família, revelando as chances de mobilidade social à época, bem como as distâncias étnicas e sociais dos grupos acima referidos. A análise da freqüência entre casamentos com cônjuges do ingroup e do outgroup ao longo de algumas gerações permite igualmente conjeturar sobre possíveis mudanças nas estratégias de reprodução social e sobre eventuais transformações na composição étnica e social de Rio Pardo. 


\section{Considerações finais}

Destacando a importância geopolítica de Rio Pardo para o povoamento do "continente", a versão poligenética sobre a formação étnica e social do seu espaço fronteiriço entre 1750 e 1850 permite entender melhor a consolidação dos interesses lusobrasileiros no vale do Jacuí e nas regiões da Campanha e das Missões, especialmente no que tange ao seu povoamento. A anexação manu militari destas regiões foi feita por milícias de mestiços e sua posterior legitimação através de acordos diplomáticos jamais seria possível sem a cumplicidade destes homens "cor de cobre, de azeitona e amulatados".

A partir de três momentos distintos (década de setenta do século XVIII, virada deste ao século XIX e meados do oitocentos) foi visto que as expedições militares contra os castelhanos contaram com um contingente expressivo de mestiços oriundos das próprias localidades onde se desenrolaram as guerras, como também de outras paragens. Há de acrescentar ainda um número significativo de europeus (portugueses, alemães, suiços, ingleses) que, por motivos profissionais e/ou mercenários, estiveram em Rio Pardo.

Com sua significativa expressão demográfica para a época, Rio Pardo oferecia igualmente um mercado promissor àqueles comerciantes ávidos por novas praças ao trato. Assim como ocorre com as famílias de militares, as de comerciantes amalgamam-se com aquelas da aristocracia fundiária. Com diferente intensidade, a mestiçagem social e étnica ocorre paralelamente entre plebeus e escravos.

Estudar o papel do mestiço na formação social de Rio Pardo é acenar com novos horizontes à historiografia sul-rio-grandense. Enquanto elemento marginal, o mestiço atuou geralmente à sombra daquela sociedade em que a fronteira era ao mesmo tempo periferia física e simbólica do centro colonizador. Como salienta Jean-Claude Schmitt, estudar os marginais significa obter uma visão mais abrangente da própria história. Trata-se de uma história da marginalidade e da exclusão que acentua não apenas os valores e as recusas da sociedade pretérita, mas também os da nossa própria sociedade. ${ }^{70}$ Assim, a história dos marginais permite não apenas lançar luz sobre estes mestiços, como também fazer a história do centro através da periferia. Ela pode evidenciar não apenas os excluídos da história como também aqueles que os excluem.

to SCHMITT, Jean-Claude. A história dos marginais. In: LE GOFF, Jacques (org.). A História Nova. São Paulo: Martins Fontes, 1990, p. 291-292. 
Em termos quantitativos a miscigenação ocorreu em maior grau no ventre das "índias da terra". Significa também dizer que o grupo indígena foi aquele que mais perdeu suas características através da miscigenação. Tape, Minuano, Charrua e, principalmente, Guarani foram se diluindo no amálgama que resultou em diversos mestiços. A formação dos novos Estados Nacionais na região platina e a definição de seus limites tiveram conseqüências drásticas para a população indígena. Marginalizada econômica e socialmente, e sem representação política, essa população sofreu uma sedentarização que serviu como catalisador do seu processo assimilação.

A etno-história pode auxiliar no árduo estudo do processo de assimilação (incorporação de elementos estranhos através da eliminação das tradições locais) desses grupos étnicos. A dificuldade para o historiador repousa, contudo, no fato de não haver uma tradição escrita entre estes grupos ou mesmo vestígios de sua cultura material significativos. Mas a produção epistolar de europeus e de mestiços oferece um manancial de informações significativas sobre diversos grupos étnicos sul-americanos. Tal como a história dos marginais, a etno-história aponta para uma crítica às formas autocentradas de entendimento das relações entre os indivíduos de diferentes grupos sociais e étnicos. Segundo Edgard Ferreira Neto, ela contribui igualmente para a gênese de novas formas de relação com a alteridade e com a singularidade.

Além da história dos marginais ou da etno-história, a história urbana permite enfocar a cidade como elemento dinâmico e catalisador da miscigenação. No caso de Rio Pardo, sua história não tem apenas ligação com a política pombalina de urbanização da América portuguesa. Sua situação geopolítica e a sua formação etno-social peculiar merecem estudos mais sistemáticos, a fim de reconstruir a história da fronteira, espaço típico dos marginais. $\mathrm{Da}$ mesma forma como o estudo do mestiço, o da cidade de Rio Pardo pode apontar não apenas novos horizontes para a história urbana, como também permitir uma visão "de fora", daquela urbe que não acompanhou a modernização de suas congêneres das áreas de colonização alemã e italiana. 